\title{
Action observation and motor imagery in performance of complex movements: Evidence from EEG and kinematics analysis
}

\author{
Javier J. Gonzalez-Rosa , Fabrizio Natali ，Andrea Tettamanti , Marco Cursi , \\ Svetla Velikova , Giancarlo Comi ， Roberto Gatti , Letizia Leocani
}

H I G H L I G H T S

- The role of motor imagery (MI) and action observation (AO) methods was examined.

- We analyzed brain correlates underlying learning of a complex coordination task.

- Different activation patterns related to EEG spectral bands were elicited by AO and MI.

- AO showed a more efficient activation of cortical resources during task execution.

- AO may be more effective than MI in promoting early motor learning.

\begin{abstract}
A B S T R A C T
Motor imagery (MI) and action observation ( $\mathrm{AO}$ ) are considered effective cognitive tools for motor learning, but little work directly compared their cortical activation correlate in relation with subsequent performance. We compared $\mathrm{AO}$ and $\mathrm{MI}$ in promoting early learning of a complex four-limb, hand-foot coordination task, using electroencephalographic (EEG) and kinematic analysis. Thirty healthy subjects were randomly assigned into three groups to perform a training period in which AO watched a video of the task, MI had to imagine it, and Control (C) was involved in a distracting computation task. Subjects were then asked to actually perform the motor task with kinematic measurement of error time with respect to the correct motor performance. EEG was recorded during baseline, training and task execution, with task-related power (TRPow) calculation for sensorimotor (alpha and beta) rhythms reactive with respect to rest. During training, the AO group had a stronger alpha desynchronization than the $\mathrm{MI}$ and $\mathrm{C}$ over frontocentral and bilateral parietal areas. However, during task execution, $\mathrm{AO}$ group had greater beta synchronization over bilateral parietal regions than MI and C groups. This beta synchrony furthermore demonstrated the strongest association with kinematic errors, which was also significantly lower in AO than in MI. These data suggest that sensorimotor activation elicited by action observation enhanced motor learning according to motor performance, corresponding to a more efficient activation of cortical resources during task execution. Action observation may be more effective than motor imagery in promoting early learning of a new complex coordination task.
\end{abstract}

\section{Introduction}

Movement observation [1,2], or imagery [3,4] has been proven as an effective tool in promoting motor learning. While motor imagery (MI) alone can improve motor performance [5], it is particularly effective when associated with physical practice [6] as compared with physical practice alone. Furthermore, some authors suggest a similar learning effect of action observation (AO) and physical practice [7-9]. Both $\mathrm{AO}$ and MI share the activation of cortical sensorimotor networks also implicated in movement execution [10-12]. For example, AO has been frequently associated with enhanced primary motor cortex (M1) excitability [13,14]. During AO, motor evoked potentials (MEPs) of agonist muscles are increased $[13,15]$. Stephan et al. $[16,17]$ have reported that 
observation of a simple aimless movement (i.e. thumb abduction) induces motor memory formation over M1, particularly if movement execution and observation are performed at the same time.

Changes of activity in different electroencephalographic (EEG) frequency bands have long been observed to reflect various aspects of cognitive activity and cognitive states of movements, such as MI or AO. Thus, a large body of evidence indicates that different EEG rhythms, mainly in the alpha $(8-12 \mathrm{~Hz})$ and beta $(14-30 \mathrm{~Hz})$ frequency range, characterize the brain activity of sensory and motor areas during voluntary movements and somatosensory processing ([18,19]; for a review, [20]). Because EEG rhythms are themselves the product of synchronized activity among and within neuronal assemblies, it is often assumed that changes in EEG power reflect underlying changes in neuronal synchrony, typically called, "task-related" or "event-related" (de-)synchronization' (ERD/S) to describe event-related changes in EEG power over the cortex. In this respect, there is a widely accepted notion that EEG desynchronization serves as an indicator of cortical activity or arousal, whereas EEG synchronization reflects a state of decreased neural excitability or inhibited thalamo-cortical circuitry [20,21].

Thus, EEG studies about AO have showed alpha band desynchronization (i.e. cortical activation) over the scalp, with the most "reactive" area located under central electrodes sites (C3 and C4) [22-24], although frontal [25] and parietal [26] foci have also been described. Cochin et al. [27] have found stronger alpha band desynchronization in the left hemisphere, mainly over central electrodes and alpha band desynchronization has also been reported to be stronger during the observation of transitive movements [28,29], and it seems to show gender differences too [30]. On the other hand, there is evidence suggesting that less alpha ERD could be an index of "neural efficiency" in sport experts [31].

Similar patterns of ERD have been described for beta band during $\mathrm{AO}$ and modulated by a participant's expertise [24,26]. In contrast, diverse studies have reported that MI modulates EEG alpha and beta rhythms during movement preparation, showing that alpha and beta bands desynchronize over the sensorimotor cortex contralateral to the imagined movement [32,33]. In this respect, Marks and Isaac [34] have described different alpha rhythm modulations depending on the type of MI used. In this study, subjects with higher imagery vividness showed posterior left alpha band desynchronization during visual imagery and posterior left alpha band synchronization during kinaesthetic imagery. Moreover, Fink et al. [35] have described low-alpha band synchronization during dancing improvisation imagery, particularly at the parieto-occipital level.

In spite of the continuous interest in investigating the role of $\mathrm{AO}$ and $\mathrm{MI}$ in motor learning [1,3-9,36-39], few studies directly compared the two learning strategies. Even though both approaches have been proven as effective cognitive motor learning techniques, $\mathrm{AO}$ seems more effective in promoting the learning of new and complex movements [40-43], which have been recently demonstrated by behavioral [40], neurophysiological [41] and neuroimaging [11] analysis. In spite of the continuous interest in investigating the role of $\mathrm{AO}$ and $\mathrm{MI}$ in motor learning [1,3-9,36-39], few studies directly compared the two learning strategies. Even though both approaches have been proven as effective cognitive motor learning techniques, AO seems more effective in promoting the learning of new and complex movements [40-43], which have been recently demonstrated by behavioral [40], neurophysiological [41] and neuroimaging [11] analysis. However, using functional magnetic resonance imaging (fMRI) [11] or transcranial magnetic stimulation and MEP [43], direct comparison of AO and MI approaches has been only conducted during the performance of simple movements (e.g., finger tapping or hand movement), whereas AO and MI during complex movements have been compared only at a behavioural level [40]. More studies are needed to further explore the functional significance of cortical activation relative to each learning strategy during a complex sequence movement. Furthermore, the role of brain activity changes (ERD/ERS) underlying learning of new and complex motor skills acquired through $\mathrm{AO}$ and $\mathrm{MI}$ as training modalities still remains unclear.

With this in mind, the purpose of the present study was to compare the neural correlates of $\mathrm{AO}$ and $\mathrm{MI}$ in relation to early learning performance of a complex four-limb hand-foot coordination task $[40,44]$, not present in the subjects' motor repertoire. To do so, we analyzed cortical bioelectrical activity of sensorimotor rhythms to $\mathrm{AO}$, MI and subsequent motor performance, together with kinematics, in a group of healthy subjects. The implications should be of great value in improving the use of $\mathrm{AO}$ and $\mathrm{MI}$ in several conditions such as sports or rehabilitation $[2,9,37,45-47]$.

\section{Methods}

\subsection{Subjects}

Thirty healthy, non athlete, right-handed volunteers (17 females, 13 males, mean age $22.9 \pm 2.3$ years) were randomly assigned to three experimental groups: action observation (AO, $n=9$ ), motor imagery (MI, $n=12$ ) and control (C, $n=9$ ). Any medical, neurological or orthopedic disorder, substance abuse or use of psychoactive drugs was considered as exclusion criterion. All subjects had normal or corrected-to-normal vision. Before the experimental procedure, each participant provided written informed consent and was screened in terms of the amount of subjects' physical activity (in terms of hours per week and years of practice), any previous elite-sport activity (in terms of years of practice, hours per week and years of inactivity), and any ability to play a musical instrument. Subjects were considered as non-athletes, and therefore eligible for the study, if they were not involved in sports for more than two training days per week. All subjects were naïve to EEG experiments and were not part of the research group.

\subsection{Experimental design}

Subjects layed in the supine position from the beginning to the end of the experimental paradigm. One pillow was placed under each wrist to allow complete flexion and extension of the hand, and a small soft cylinder was positioned under the upper neck to keep the occipital bone raised, thus allowing correct placement of EEG occipital electrodes. The bed was positioned at the center of the acquisition volume, and it was surmounted by a computer screen (17 in.) fixed on a wooden support, $70 \mathrm{~cm}$ above subject's face. Experimental paradigm (Fig. 1), consisting of a 3-min pretraining period, a 7-min training, and a 3-min task execution, began when subjects were correctly lying on the bed, as relaxed as possible. During the pre-training period all participants, irrespective of the group assignment, had to rest in a silent room without any distraction, for $6 \mathrm{~min}$ ( $3 \mathrm{~min}$ with eyes closed, to get acquainted with EEG recording, followed by 3 min with eyes open serving as EEG baseline, see below). Then, they were asked to read written instructions and figures explaining how to execute the motor task, projected for $90 \mathrm{~s}$ on a screen. Movement consisted in a four-limb hand-foot coordination task, consisting in simultaneous sequential flexions and extensions of hands and feet in the parasagittal plane. The right hand and foot had to be moved in the same angular direction (in-phase or isodirectional movement), while moving the left hand and foot in opposite angular directions (anti-phase or antidirectional movement) [44]. After the instruction period, all participants were explicitly asked if they had fully understood the task and the instructions. Furthermore, to facilitate understanding of the task, two operators (one on the right side and one on the left side) simultaneously passively moved hands and feet of the 


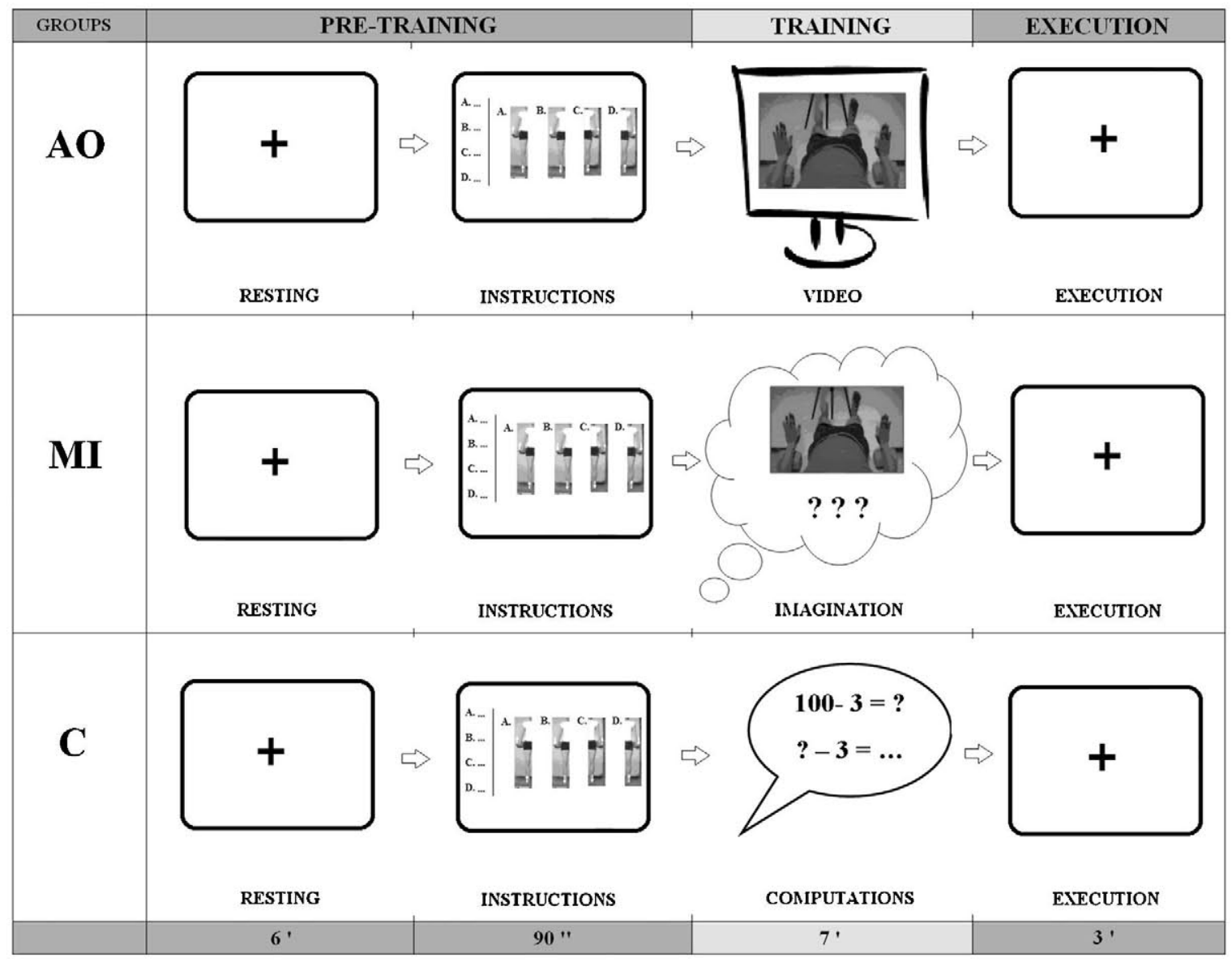

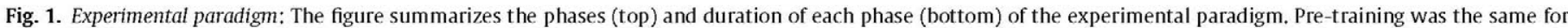

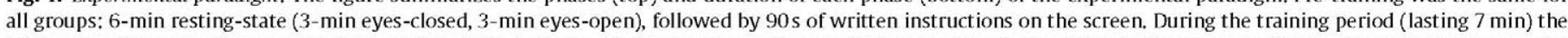

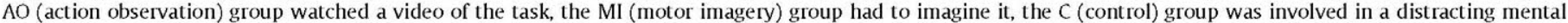
computational task. Task performance (execution) lasted for $3 \mathrm{~min}$.

subjects, while a metronome beat the frequency of $1 \mathrm{~Hz}$ at which subject would be requested to perform the task. This passive trial, lasting about $2 \mathrm{~s}$, consisted of one single cycle of flexion and extension of hands and feet.

The training differed between groups (Fig. 1). The AO group watched a 7-min continuous video, alternatively displaying a male and a female performing the task from four different perspectives (cranial, caudal, lateral left, lateral right). The MI group had to mentally simulate the movement for $7 \mathrm{~min}$. In the present study, MI was defined as an "integrated visual-kinetic imagery". In fact the MI task required both the representation of the spatial components of the perceived environment (i.e., "visual imagery" by explanatory pictures with real human figures taken at the same recording scenario) and the kinesthetic feeling of the movement (i.e., "kinetic imagery ", which was also passively experienced by all participants as well). To avoid any extra advantage in the MI group with respect to the $\mathrm{AO}$ or $\mathrm{C}$ group, no movement imagery questionnaires (which often to include different items to imagine with different levels of actual movements before task performance) were used to evaluate the vividness of movement imagery in the visual and the kinesthetic dimensions MI. The C group mentally executed a 7 min $n$-count task, which was a control distracting condition: they had to sequentially subtract a given number from 100 until they reached zero; then new numbers were provided to be subtracted from 100 until the $7 \mathrm{~min}$ had elapsed. To ensure that subjects of the $C$ group were actually performing the computation (e.g. not imagining the task) they were asked, every $40 \mathrm{~s}$, which number of the sequence they had reached. Regardless of experimental group, all subjects were forbidden to actually perform the task during both pre-training period and training period.

Task execution started immediately after the training period: following the beat of a metronome, subjects had to perform the movement for $3 \mathrm{~min}(180 \mathrm{~s})$ at the frequency of $1 \mathrm{~Hz}$. After task execution we asked subjects if they had understood the task correctly, if they had not, they would have been excluded from statistical analysis.

Preliminary tests carried out before to start the present study revealed that there was a strong tendency in some participants to become distracted or not understand the instructions very well during the training condition or when instructions were provided simultaneously with the metronome sound, whereas other participants (from all experimental groups) appeared to obtain an important behavioral advantage in comparison to others during the trainings conditions. Therefore, in order to have as homogeneous as possible in the learning and training conditions across the three experimental groups, we decided to use the metronome only during the movement execution. Given that in our study there were three different training conditions, the mean reason to use the metronome during the motor task was to provide a pace to thus avoid that the high variability of performance could interfere with the number of movements carried out for each group.

\subsection{EEG recording and analysis}

The EEG signal was recorded for $6 \mathrm{~min}$ at rest pre-training (eyes closed and open, 3 min each), for 7 min during training, (TRA) and 
for 3 min during task execution (EXE). During TRA and EXE conditions subjects kept always their eyes open. In order to reduce blinks, subjects were told to look at a fixation cross on the computer screen; only subjects who watched the video were explicitly told to avoid blinks, given the high tendency to blink in this condition. EEG was recorded from $30 \mathrm{Ag}-\mathrm{AgCl}$ surface electrodes mounted on a cap (Electro-cap International, Eaton, $\mathrm{OH}$ ) according to the 10-20 international system. Electrode impedance was kept below $10 \mathrm{k} \Omega$. EEG signal was amplified (BrainAmp Amplifiers, Brain products, $\mathrm{Co}$, Munich, Germany), filtered between 0.5 and $70 \mathrm{~Hz}$ ) and digitized ( $250 \mathrm{~Hz}$ sampling frequency). Bipolar surface EMG was recorded bilaterally from extensor carpi radialis (R-EXT, L-EXT) and tibialis anterior (R-TA, L-TA) in order to verify muscle relaxation during resting and training periods.

Changes in cortical activation with respect to the 3-min eyesopen resting were quantified by means of task-related power (TRPow) [48]. Before performing analysis of TRPow, EEG signals were digitally filtered, with a low-cut of $1 \mathrm{~Hz}$ and a high-cut of $50 \mathrm{~Hz}$. Each condition (Resting, TRA and EXE) was segmented into non-overlapping epochs of $1024 \mathrm{~ms}$ and visually checked for EEG artifacts; epochs containing artifacts were rejected. During the TRA period, we verified through visual inspection and recording of EMG and kinematics from each limb to exclude slight muscle activation and thus contamination of the covert performance of each experimental condition. For each period, at least 90 epochs were included for each subject (mean $=131 \pm 39$ ) and the number of epochs did not differ for the three groups $(p=0.470)$. A Hamming window was used to control for spectral leakage, and a discrete Fourier transform was computed for each epoch.

The role of theta or gamma band activity over motor or sensorimotor regions during motor movement performance has not been completely clarified [49]. Moreover, the role of alpha and beta ERD/ERS patterns on scalp EEG during compound limb MI or AO combing left/right hand and foot is not well known $[50,18]$. We focused on the EEG spectral profile in the range of "more classical" alpha and beta bands with a width of $4 \mathrm{~Hz}$, which was calculated in individually selected frequency bands that were reactive during movement execution. Thus, individual alpha frequency (IAF) peak was defined as the frequency showing its power in the extended alpha range $(7-13 \mathrm{~Hz})$. To account for the inter-individual alpha peak variability (frequency of maximal contribution of band power), the power was estimated with a width of $2 \mathrm{~Hz}$ centered in IAF peak $[18,51]$. Beta frequency band was inspected visually for each subject and its power was individually estimated within a individual narrow band of $4 \mathrm{~Hz}(18-22 \mathrm{~Hz})$ as these beta frequencies were held constant for each subject over the experimental conditions $[18,52,53]$.

For each subject and for each frequency band, we computed mean power at each electrode, in each condition (resting, TRA, EXE). The power values were transformed to relative power changes using power from eyes-open resting condition [54,55]. To reduce the effect of intersubject and interelectrode variability of absolute spectral power values, task-related power for each subject, frequency band and electrode position was computed for both TRA and EXE conditions, according to the following equation:

TRPow $_{X}=\frac{\text { Pow }_{X}-\text { Pow }_{\text {resting }}}{\text { Pow }_{\text {resting }}}$

where Pow $_{x}$ refers to the power value during either TRA or EXE condition. Thus, decreases in TRPow (event-related desynchronization-ERD or cortical activation) are expressed as negative values, whereas increases of TRPow (cortical idling or synchronization) are expressed as positive values. TRPow values were used to generate topographical TRPow maps.
For statistical analysis, in order to stabilize the variances of the power data and for selection of electrodes and regions of interest (ROI) we performed a log transformation of power values. We used log-transformed power values to calculate TR(log Pow), according to the following equation:

$\operatorname{TR}\left(\log \operatorname{Pow}_{X}\right)=\log \left(\right.$ Pow $\left._{X}\right)-\log \left(\right.$ Pow $\left._{\text {resting }}\right)$

According to this transformation, negative values of TR Log Pow represent ERD, while positive values represent ERS. We identified six ROI by averaging TR(log Pow) for each electrode cluster: left frontocentral [Left-FC: FC1, C3, FC5], right frontocentral [Right-FC: FC2, C4, FC6], left centroparietal [Left-CP: CP1, CP5], right centroparietal right [Right-CP: CP2, CP6], left parietal [Left-P: P3, P7], right parietal [Right-P: P4, P8]. We compared average TR(logPow) for each condition and frequency band (alpha and beta) using a mixed-design repeated measures ANOVA, with ROI (frontocentral-FC; centroparietal-CP; parietal-P) and Hemisphere (left or right) as within-subject factors, and Group ( $\mathrm{AO}, \mathrm{MI}$ or $\mathrm{C}$ ) as betweensubject factor. Resting EEG activity (log-transformed power values) was also investigated for each frequency band and across different groups. Distribution of data was assessed using the Shapiro-Wilk test of normality, and the Greenhouse-Geisser method was used where necessary to correct for non-sphericity. Bonferroni correction and post-hoc $t$-tests (paired and independent) were used to further investigate for possible groups differences and interactions effects. Statistical significance was set at $p<0.05$.

\subsection{Kinematic acquisition and analysis}

In order to obtain wrist and ankle kinematics we used 6 videocameras (Elite, BTS-Milano) recording the movement of 12 passive markers, placed bilaterally onto the following points: head of the radius, ulnar styloid process, head of the fifth metacarpal bone, head of the fibula, lateral malleolus, head of the fifth metatarsal bone. Data were recorded using Biomech $v 1.5$, with a $100 \mathrm{~Hz}$ sampling frequency. 3D movement reconstruction was obtained using Tracklab v1.0. Kinematic analysis was carried out with Smart Analyzer v1.1. Each 180 -s full track was split into six consecutive 30-s blocks.

The kinematic outcome was the error time (ET, s), and it was defined as the sum of periods of incorrect performance [44]. We defined three types of incorrect performance: phase error occurred when one limb was moved in the opposite direction to which it should have moved; pause error occurred when one limb was not moved for more than $1100 \mathrm{~ms}$; amplitude error occurred when the angular displacement of one limb was lower than half of its average angular displacement during the 30 -s block considered for analysis. Two independent operators visually checked the tracks, detecting periods in which subjects moved their limbs incorrectly; when disagreement occurred a third operator evaluated the tracks. We thus obtained six values of ET per subject $\left(\mathrm{ET}_{1}, \mathrm{ET}_{2}, \mathrm{ET}_{3}, \mathrm{ET}_{4}, \mathrm{ET}_{5}, \mathrm{ET}_{6}\right)$ each corresponding to one of the 30 -s blocks ( $\mathrm{ET}_{1}$ corresponds to seconds 0-30; $\mathrm{ET}_{2}$ to seconds 30-60; $\mathrm{ET}_{3}$ to seconds 60-90, etc.)

Repeated measures ANOVA was performed over ET values, with Time $\left(\mathrm{ET}_{1}, \mathrm{ET}_{2}, \mathrm{ET}_{3}, \mathrm{ET}_{4}, \mathrm{ET}_{5}, \mathrm{ET}_{6}\right)$ as within-subjects factor and Group (AO, MI, C) as between-subjects factor.

\subsection{Correlations}

To further describe the relationship between cortical activity during training ( $\mathrm{AO}, \mathrm{MI}, \mathrm{C}$ ) and the resulting cortical activity and motor performance during execution, linear regression analyses were carried out on the data. Thus, kinematic data (mean ET) from significant blocks (no. of errors during the first $30 \mathrm{~s}$ ) and logtransformed TRPow values in IAF and beta frequency bands from 

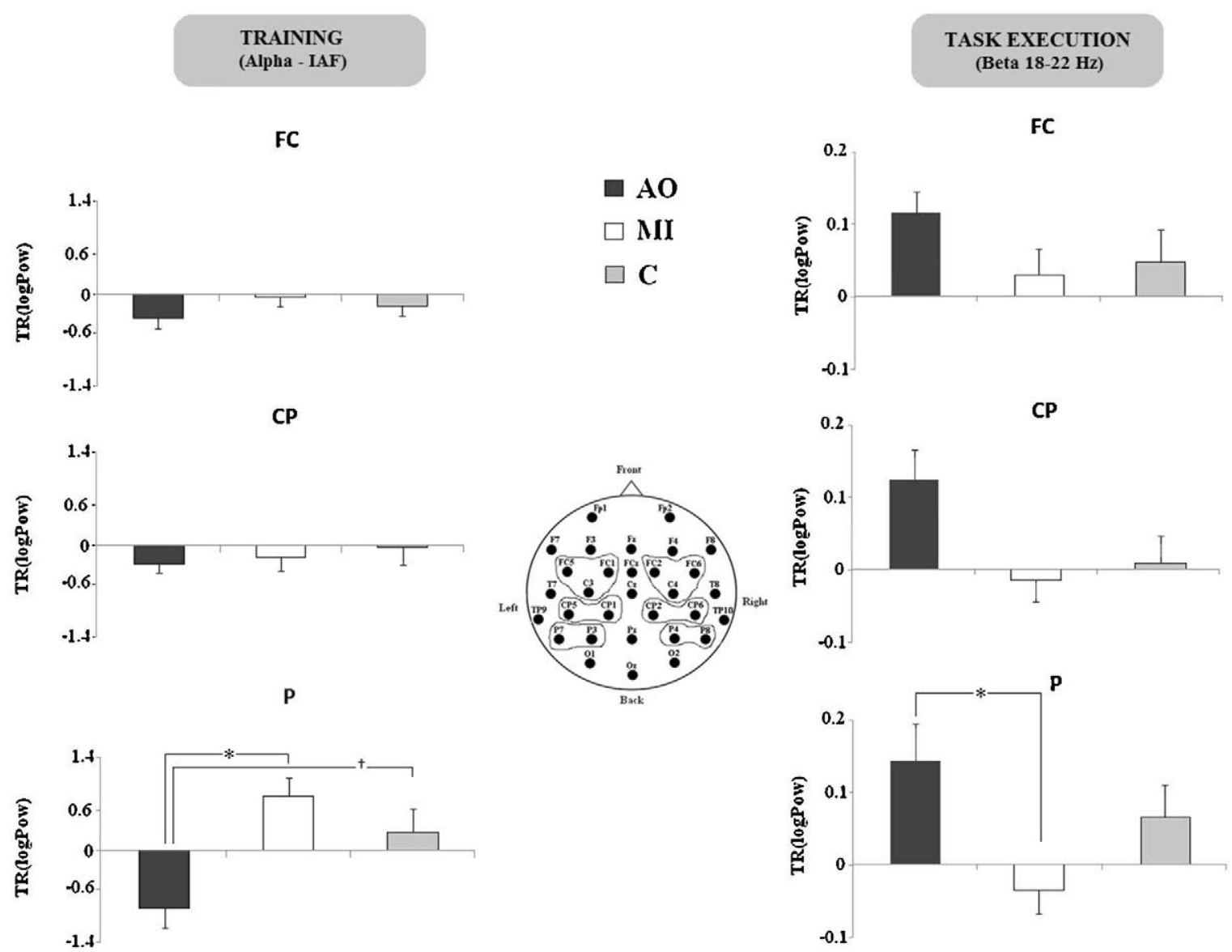

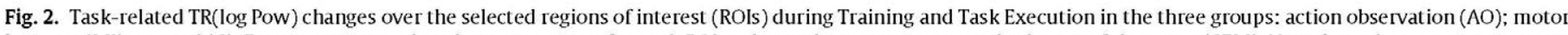

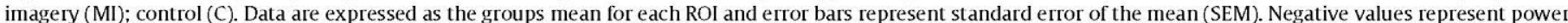

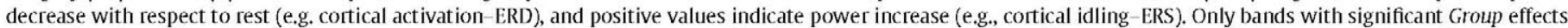

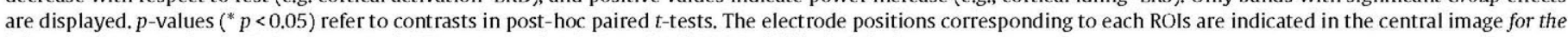
left and right hemisphere; FC: fronto-central; CP: centro-parietal; P: parietal. IAF: Individual alpha frequency.

the different ROIs (FC, CP, P) were entered in a stepwise fashion into a linear regression model to determine the strongest cortical activity predictor of movement execution. We used a conservative forward stepwise selection (entrance criterion $p=0.05$ and exit criterion $p=0.10$ ) because the study is exploratory.

\section{Results}

Fig. 2 summarizes results of the post-hoc analysis and Fig. 3 summarizes the cortical activation patterns for the three different experimental groups. Fig. 4 illustrates the kinematic results of the performance time course.

\subsection{EEG-Resting}

During the resting period, ANOVA revealed no significant main Group effect (alpha, $p=0.65$; beta, $p=0.52$ ) or interactions for any of the frequency bands analyzed.

\subsection{EEG-Training}

Movements (measured by EMG or Kinematic activity) during the TRA period in the three experimental groups were extremely infrequent, and if they were present, these segments of EEG signal were not further considered for the EEG analysis. During training, AO and MI were associated with a diffuse sensorimotor alpha and beta desynchronization (i.e., reduced TRPow values) (Fig. 3). No relevant alpha TR(log Pow) changes were seen in the Control group, except for a weak cortical activation in fronto-central regions bilaterally.

Repeated measures ANOVA showed a significant interaction $R O I \times \operatorname{Group}\left(F_{(4,52)}=4.18, p=0.02\right)$, revealing post-hoc paired $t$ tests significant greater ERD values in the AO group than the MI group over bilateral parietal regions $(p=0.03)$ (Fig. 2). There also was a trend towards significance between AO (greater ERD) and $\mathrm{MI}$ and $\mathrm{C}$ groups for frontocentral regions $(p=0.79)$. No differences involving hemisphere or between either $\mathrm{AO}$ and $\mathrm{C}$ groups or $\mathrm{MI}$ and C groups were found.

A similar pattern of cortical activation was observed on beta ERD, with no statistically significant effects.

\subsection{EEG-Task execution}

During task execution, reactivity of sensorimotor rhythms(ERD: power reduction; ERS power increase) over the centroparietal and frontal ERD was observed in all groups, predominantly for the MI and $\mathrm{C}$ groups and less evident for the AO group (Fig. 3). Repeated measures ANOVA showed a significant Group effect in beta band during movement execution $\left(F_{(2,26)}=7.20, p<0.01\right)$. A significant interaction $R O I \times$ Group was also found beta band $\left(F_{(4,52)}=3.60\right.$, $p=0.02$ ], indicating post-hoc testing a significantly stronger parietal ERS (lower ERD) in the AO compared with the MI and C groups ( $p=0.02$ and 0.04 , respectively) (Fig. 2). A similar pattern of cortical activation was also observed on IAF ERS, with no statistically significant effects. 


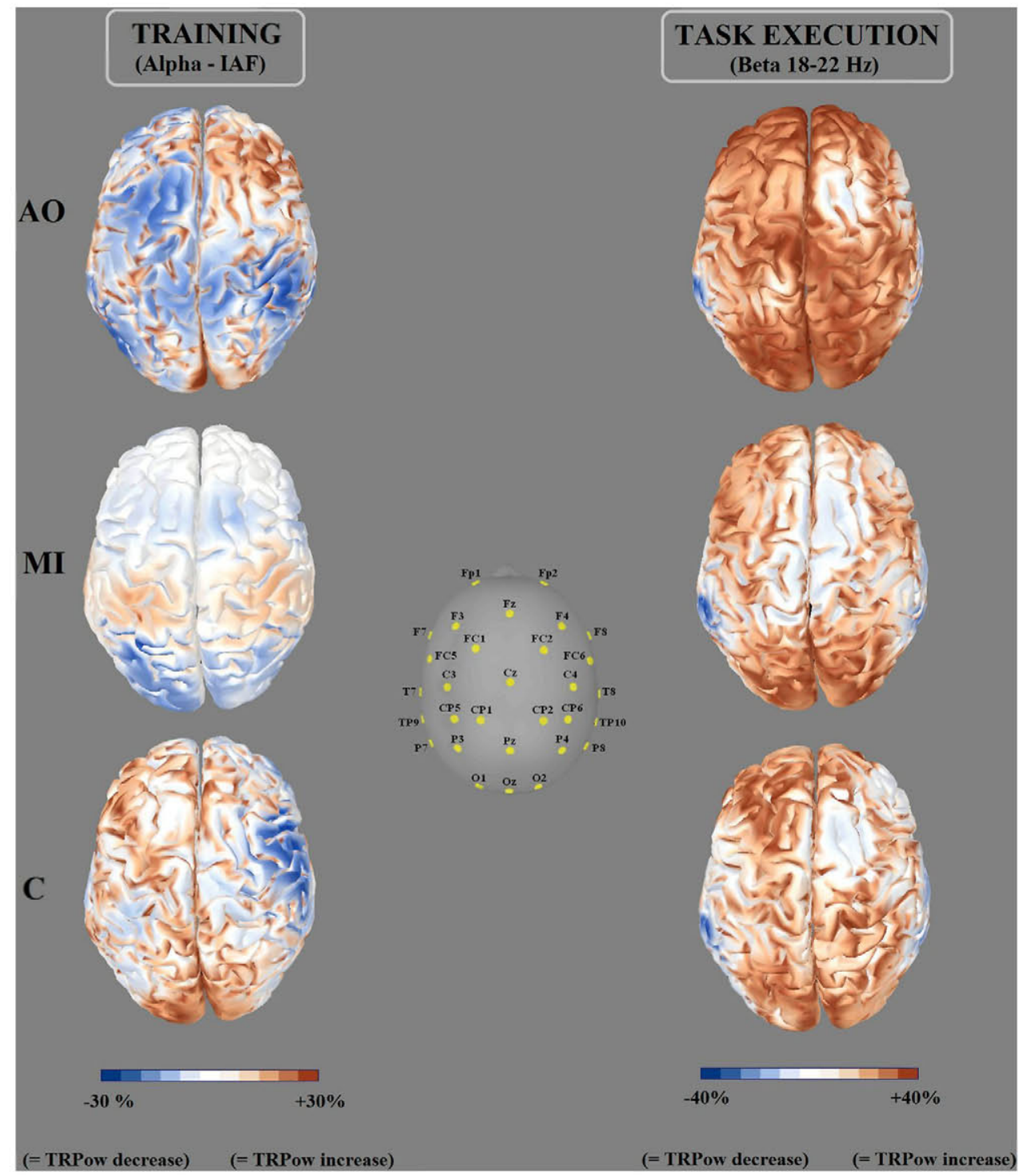

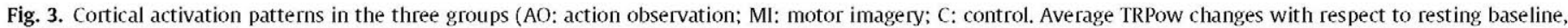

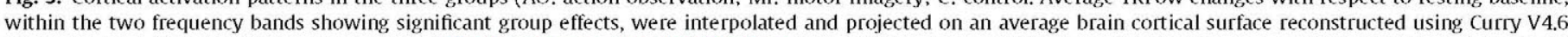

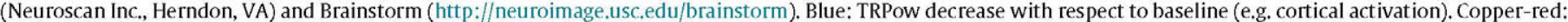

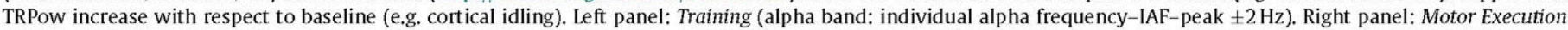
(beta band: $18-22 \mathrm{~Hz}$ ). (For interpretation of the references to color in this figure legend, the reader is referred to the web version of this article.)

\subsection{Kinematics}

Groups resulted homogeneous for sex, age, physical and musical activity (Kruskal-Wallis one-way ANOVA: n.s.). Data obtained from one subject in the MI group were excluded from the analysis because he reported not understanding the task. Results of error time (ET) at kinematic analysis are shown in Fig. 4. A significant effect was found for factor Time $\left[F_{(5,130)}=6.58, p<0.01\right]$; in fact post-hoc analysis revealed that all groups showed significant reduction of mean ET from the first 30-s block (ET1) to the second one (ET2) $(p<0.01)$. A significant Group effect $\left[F_{(2,26)}=3.73\right.$, $p=0.03$ ] was also present, with AO group performance significantly better than the MI group after application of the Bonferroni posthoc adjustment test $(p=0.03)$.

\subsection{Relationship between EEG reactivity during training, execution, and behavioural performance}

Regression modeling tested the relative association between all EEG variables of our study (during training and execution periods) and the correct performance of movement. TR(log Pow ) in beta band over parietal sites during task execution was the only variable selected in the final model $\left(r=0.54 ; R^{2}=0.27 ; p=0.04\right)$. Thus, among all EEG measures and ROIs, beta synchronization in bilateral parietal regions was the strongest predictor in the model for the movement execution, revealing that those subjects with weaker beta ERD or greater beta ERS (i.e., increased TR(log Pow) values) also performed movement execution much better, with a reduction of mean ET (first 30-s block) (Fig. 5).

\section{Discussion}

The purpose of this study was to compare the effectiveness of $\mathrm{AO}$ and $\mathrm{MI}$ in promoting early learning of a complex four-limb coordination task. During the training period, AO was associated to the greatest sensorimotor EEG activations, as from the alpha desynchronization over frontocentral and bilateral parietal areas. During actual motor performance, the AO group also had the best kinematic performance and the lowest amount of cortical activation, as from beta synchronization over parietal areas. The consistency 


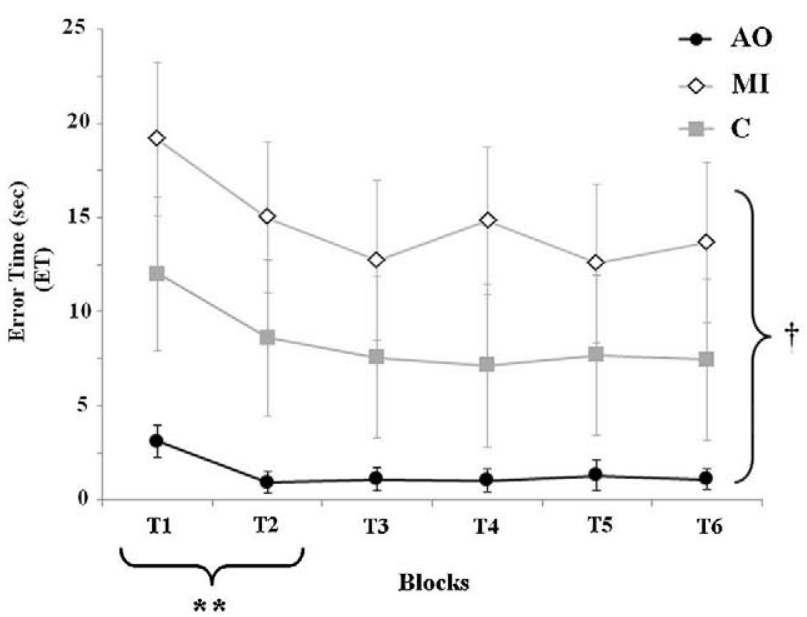

Fig. 4. Performance time course-kinematic analysis. Group average data (mean and standard error) of error time (ET) over a block of 30 s (T1, T2, T3, T4, T5, T6) during motor performance. For each subject, ET represents the mean error time during in-phase and anti-phase movements of the four limbs. $\dagger$ Significant Group effect $\left[F_{(2,26)}=3.73, p=0.03\right.$ ), with significant post-hoc difference between $\mathrm{AO}$ and $\mathrm{MI}\left(p=0.03\right.$, Bonferroni corrected). ${ }^{* *}$ Significant Time effect $\left[F_{(5,130)}=6.58 ; p<0.01\right)$, with significant post-hoc difference between Time 1 and Time $2(p<0,01$, Bonferroni corrected).

between EEG and kinematic findings was also confirmed at regression analysis, indicating that beta synchronization during task execution was the best predictor of movement performance. Taken together, these results may suggest that specific parietal and fronto-central alpha desynchronization may reflect focused activation involved in learning a complex coordination movement during $A O$. In addition, the best behavioural performance in AO group seems to be associated with increased in parietal beta synchronyzation and with the need for a lower recruitment of cortical resources compared with the MI group. Consistently, there is evidence in the literature that frontal and different subregions of parietal cortex are

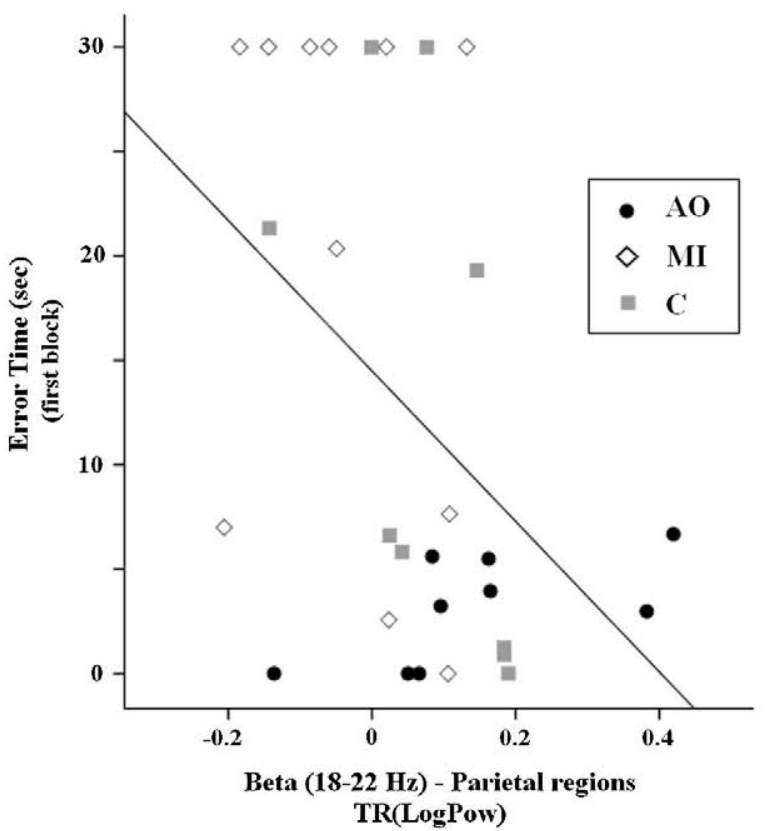

Fig. 5. Correlation scatterplot of the results obtained from the stepwise multiple regression analysis. Regression modeling tested the relative association between all significant EEG variables and motor performance. The amount of beta ERS (e.g., cortical idling) during movement execution in bilateral parietal regions was the only variable selected in the final model $\left(r=0.54 ; R^{2}=0.27 ; p=0.04\right)$ active during observation of intransitive movements [11,12,56], and may differentially interact during the cognitive processing of upper and lower limb movements [57]. Moreover, this cortical activity is modulated by several variables, such as perspective $[58,59]$, the observer's posture [60], handedness [61], or the part of human body being imagine [62]. In particular, motor experience seems to have a crucial role in the quality of cortical activation during AO. For example, better activations have been described during the observation of familiar acts $[28,63,64]$ as opposed to novel acts.

MI has also been demonstrated to be effective in activating sensorimotor networks [65-68]. Interestingly, cortical activations are differentially activated by the sensory system (kinaesthetic rather than visual) involved in mental rehearsal process [66] but cortical activity during MI appears to be modulated both by imagery ability [69] and motor experience $[35,70]$.

There is strong evidence suggesting that the mirror neuron system may share common cortical substrates to AO, MI and actual movement; a fronto-parietal network involving visuomotor neurons [12,71-74]. Mirror neurons were described for the first time in the brain of the macaque monkey [75]. They fire both when the monkey executes an object-directed action (transitive movement) and when it observes someone else performing the same action, thus encoding the purpose of an observed action (e.g. grasping) and the motor intentions of the observed individual (e.g. grasping to eat) [75-77]. Several works demonstrate the existence of a human homologue of monkeys' mirror neuron system, involving parietal and frontal areas $[53,72,78-80]$, whose function is not only related to action and intention encoding, but also to intransitive actions encoding (e.g. wrist flexion and extension) and imitation learning [12,78,81].

The rationale of our work particularly relies on the aforementioned characteristics of human mirror neurons. In our findings, AO enhanced learning compared with MI and, as previously hypothesized by Horn et al. [36], possibly was related to a more efficient activation of the mirror neuron frontoparietal system, as well as a much better synchrony in the corticospinal system [82]. Previous works reported sensorimotor rhythms desynchronization to action observation [22-26,28,31], motor imagery [34,35,83,84], or even during listening to action-related verbs [85]. Motor imagery appears to be also related to internal thinking [86] and to internally versus externally directed attention by alpha synchronization [87].

Interestingly, desyncrhonization of the alpha (or 'mu') rhythm has been reported associated with activation of the mirror neuron system [88]. This evidence has been further supported by electrophysiological and neuroimaging studies in humans, which have showed that during AO, alpha/mu desynchronization is primarily associated with activity in the inferior parietal cortex and other frontal areas associated with the mirror neuron system, such as the supplementary motor area and the dorsal premotor area [56,89,90]. Our data are consistent with this view and suggest that motor activation during AO may reflect subthreshold preparation of correct responses. This activity can be modulated by movement observation, likely by modifying internal motor representations and the related neural networks involved in processing sensorimotor control.

We believe that our results of AO training being associated with a stronger cortical activation and a subsequent better motor performance, compared with MI, are not in contrast with the amount of evidence demonstrating that $\mathrm{MI}$ is an effective tool in motor learning [3-6]. Furthermore, MI has been reported to be associated with EEG changes similar to those observed during actual motor performance, despite the fact that observation of movement achieves a much better performance than imagery conditions [91]. In the present study, MI designated movements that were not previously observed or executed, but instead mentally simulated as if they were. Our findings seem to indicate that difficulties in imagining 
the unfamiliar movement were reflected in the bad performance, suggesting that the unfamiliarity of the type of movement may promote inaccurate MI and, therefore, unsuccessful attempts of subsequent performance.

Our EEG findings are not directly comparable, and the mental processes associated are also difficult to interpret, which is due to the nature of our MI condition. Because the imagery exercises in the present study were indeed detailed and oriented towards either the visual or kinesthetic aspects of the task, a clear distinction between visual or kinetic imagery could not be explicitly made in our study $[92,93]$. In this respect, some authors have categorized MI either as a self-visualization of action (visual imagery or third-person process) or as a mental simulation of movement, associated with a kinesthetic feeling (kinetic imagery or first-person process) [91,92]. This distinction has been further supported by behavioral and functional (EEG and neuroimaging) works, indicating that kinesthetic and visual motor imagery seem to activate different neural networks and different cortical activation patterns [34,66,91,94]. However, given that all our experimental groups, including the MI group, had to read written instructions and to watch explanatory figures (i.e., visual imagery or third-person process), and given that the kinesthetic feeling of the movement was also passively experienced by all participants as well (i.e., "internal" kinetic imagery), we speculate that the EEG activation pattern observed in our MI condition may have involved both sparse somatomotor and visual representations of movement, although the 'potential' positive effects of MI practice to learn the motor task described in other studies and on motor performance was lacking, likely due to the relative difficulty of imagining the challenging and unfamiliar action of our task [95].

Instead, the present data must be interpreted in the context of the specific paradigm used. First, the task was quite complex and movements were not finalistic or familiar to the subjects. The most likely explanation for a weaker sensorimotor activation in the MI group during training is task difficulty and unfamiliarity, which may have led to difficulty in mental representation of the movement required to imagine. In fact, task explanation was provided by written instructions for $90 \mathrm{~s}$, followed by some only two-cycle passive movements of the limbs. Subjects in the AO group could take advantage of a third kind of instruction during training by watching the video. Apart from the cortical facilitations provided by observation of the video, it is likely that the AO group could better understand the task, while the MI and C groups could not benefit on written instructions and passive movement only, without the advantage of additional visual exposure to the task. A minor and dispersed activation pattern involving different cerebral areas in the Control group during mental calculation was what we expected, as this task does not require specific activation of the sensorimotor EEG bands investigated here [96-98].

Evidence for differences in performance and pattern of cortical activation in humans and monkeys associated to goal-directed or indirected behavior has been also demonstrated [99,100]. Despite attempts to explain the task and ensure that all subjects had understood before the training period, we cannot exclude the possibility that the lack of adequate sensorimotor activation during the motor imagery task in the MI group was just related to the fact that subjects had not understood the task properly and therefore could not imagine it, or simply they did not imagine as instructed. This, however, it is a common problem in most motor imagery experiments. However, the difficulty in understanding or imagining the requested performance has to be considered when the MI is provided for facilitating a novel and complex motor task.

Notably, our results of TRPow analysis during task performance are in line with those of kinematic analysis. One explanation for our findings may be related to the pattern of muscle performance itself. Either correctly or incorrectly, all subjects moved their extremities during task execution. As subjects in the AO group executed the task with correct alternation of flexions and extensions (i.e. low values of ET), they were able to alternate muscle contraction and muscle relaxation, and, consequently, to alternate activation (desynchronization) and deactivation (synchronization) of cortical areas involved in motor control $[53,83,101,102]$. Subjects in the $\mathrm{MI}$ and $\mathrm{C}$ groups, on the contrary, had to change movement direction very frequently because they made more movement mistakes (i.e. higher values of ET), hence they were in a constant state of muscular activation, and consequently, of cortical activation. In this respect, a greater amount of beta desynchronization may be interpreted as a correlate of increased cortical activation and excitability $[53,103,104]$.

One limitation in interpreting changes in beta rhythms in the present study is related with the task-related analysis. Block design does not allow to distinguish, in case of significantly lower ERD or higher ERS, between an effect mediated by lower ERD, higher ERS or a combination of the two over the movement cycles. The eventrelated analysis, allowing to describe the time-course of cortical activation (ERD) and inactivation/idling (ERS) [105,106] could not be performed in this case given the cyclic, continuous nature of the movement sequence of our task, without spacing between single movements.

On the other hand, it is possible that the AO group showed a greater efficacy in learning and executing a novel motor task than the MI and C groups, at least in an early quick phase of the motor learning process. Our kinematics and EEG results suggest that better performers were associated with, not only enhancement of activation (stronger alpha ERD) during training, but also with decreased neural activations (greater beta ERS) during movement execution, which might be reflective of greater neural efficiency in the brain networks underlying performance $[107,108]$. This suggests a more efficient neural code for controlling the motor movement and is consistent with the enhancement of beta synchronization following successful movement $[109,110]$, particularly during gross movements such as the wrist [111], as well as improved motor performance [82]. The regression modeling results of our study are in line with these mentioned findings, revealing that an increase in beta synchrony (during task execution) accounted for greater variance than an increase in alpha desynchronization (during training) in explaining the improved motor performance. Thus, beta activity has been related to increased alertness in thalamo-cortical systems [112], and increases with increased precision of motor tasks [113]. In this respect, post-movement beta synchronization is considered to reflect the cortical processing of afferent muscle inputs $[114,115]$. Beta activity may be associated with a more efficient processing of peripheral feedback required for monitoring the different stages of movements [116-119]. In the AO group, a higher beta synchronization following each movement cycle may have led in our findings to an overall weaker beta desynchronization considering the whole movement period analyzed.

Interestingly, our results (Fig. 3) showing specific task-related alpha desynchronization (i.e., cortical activation) and beta synchronization (i.e., cortical idling) in parietal regions are also consistent with recent evidence that different subregions of parietal cortex can be selectively recruited by the processing of limb movements and strongly involved in limb gesture processing [11,57]. Moreover, our findings also support neuroimaging studies using different cognitive and motor tasks, which have also demonstrated the association between fast/slow learning and decrease/increase in activity within a fixed network of regions, or recruitment of additional regions as the skill is learned [120-124]. Furthermore, neurophysiological $[41,125,126]$ and fMRI [127-129] findings suggested higher degree of cortical activation for more demanding motor tasks. This appears to also be the case in our study, with the most successful task 
execution associated with the lowest degree of cortical activation (i.e. cortical synchronization) in the $\mathrm{AO}$ group.

\section{Conclusions}

We showed that bioelectrical cortical activation to AO and MI are associated with the motor learning process of a complex motor coordination task. These findings are consistent with previous evidence pointing to the use of $\mathrm{AO}$ as an effective tool in motor learning, probably through activation of the mirror neuron system. One possible explanation for the superiority, in our results, of $\mathrm{AO}$ compared with $\mathrm{MI}$ in promoting motor learning may rely in the specific task used. The type of movement (afinalistic, unfamiliar), together with the pre-training instructions (brief exposure to written description and passive movement) probably made the process of motor imagery too difficult to be as effective as $\mathrm{AO}$ in promoting early motor learning. In our findings $\mathrm{AO}$, resulting in better learning compared with MI, also elicited a stronger activity of the sensorimotor cortex during training, resulting in a lower amount of cortical activation during task execution. Alternatively, it would be possible to hypothesize that engagement in AO may increase arousal and self-efficacy, thus having a positive effect on motivation and self confidence during movement execution.

The present data point out to the functional role of sensorimotor rhythms during motor learning and can be a partial confirmation of the neural efficiency hypothesis. Specifically, practice after AO may decrease task demands, improve behavioral performance, and produce activation decreases in task-relevant brain areas, with lower allocation of cortical resources associated with improved performance. Another possible mechanism underlying the efficacy in our study of $\mathrm{AO}$ with respect to $\mathrm{MI}$ in learning a novel complex motor task, may be due to increased corticocortical coupling, as indexed by coherence, between parietal, premotor, and motor networks, and without excluding the possible contribution across others EEG frequency bandwidths. Taken together, our results underline the importance of using a correct strategy in acquiring novel motor competence, suggesting that during $\mathrm{AO}$, subjects appear to process and collect sensory and motor information relevant to action in an effective and efficient manner, which allowed them to apply a series of decision making strategies appropriate to defining which movement sequence to perform, and activating control processes such as feed-forward control during motor execution $[40,130]$. These findings provide new possibilities for the ability to coordinate upper and lower limbs and for motor learning by $\mathrm{AO}$ in comparison to MI, at least in the early phase of the motor learning process, which should be considered during neurorehabilitation and physical training.

\section{Acknowledgements}

This work was supported by the European Commission (7th Framework Programme) through Intra-European Marie Curie fellowship to Javier J. Gonzalez-Rosa (Grant: 221088; principal investigator: Letizia Leocani).

\section{References}

[1] Shea $\mathrm{CH}$, Wright DL, Wulf $\mathrm{G}$, Whitacre $\mathrm{C}$. Physical and observational practice afford unique learning opportunities. J Mot Behav 2000;32(1):27-36.

[2] Wulf $G$, Shea C, Lewthwaite R. Motor skill learning and performance: a review of influential factors. Med Educ 2010;44(1):75-84.

[3] Allami N, Paulignan Y, Brovelli A, Boussaoud D. Visuo-motor learning with combination of different rates of motor imagery and physical practice. Exp Brain Res 2008;184(1):105-13.

[4] Yaguez L, Nagel D, Hoffman H, Canavan AG, Wist E, Homberg V. A mental route to motor learning: improving trajectorial kinematics through imagery training. Behav Brain Res 1998;90(1):95-106.
[5] Gentili R, Han CE, Schweighofer N, Papaxanthis C. Motor learning without doing: trial-by-trial improvement in motor performance during mental training. J Neurophysiol 2010;104(2):774-83.

[6] Gentili R, Papaxanthis C, Pozzo T. Improvement and generalization of arm motor performance through motor imagery practice. Neuroscience 2006;137(3):761-72.

[7] Hayes SJ, Elliott D, Bennett S]. General motor representations are developed during action-observation. Exp Brain Res 2010;204(2):199-206.

[8] Heyes CM, Foster CL. Motor learning by observation: evidence from a serial reaction time task. Q J Exp Psychol Sec A: Hum Exp Psychol 2002;55(2):593-607.

[9] Vinter A, Perruchet P. Implicit motor learning through observational training in adults and children. Mem Cogn 2002;30(2):256-61.

[10] Holmes P, Calmels C. A neuroscientific review of imagery and observation use in sport. J Mot Behav 2008;40(5):433-45.

[11] Lorey B, Naumann T, Pilgramm S, Petermann C, Bischoff M, Zentgraf K, et al Neural simulation of actions: effector- versus action-specific motor maps within the human premotor and posterior parietal area? Hum Brain Mapp 2014:35(4):1212-25

[12] Lui F, Buccino G, Duzzi D, Benuzzi F, Crisi G, Baraldi P, et al. Neural substrates for observing and imagining non-object-directed actions. Soc Neurosci 2008:3(3-4):261-75.

[13] Gangitano M, Mottaghy FM, Pascual-Leone A. Phase-specific modula tion of cortical motor output during movement observation. NeuroReport 2001;12(7):1489-92.

[14] Lepage JF, Tremblay S, Theoret H. Early non-specific modulation of corticospinalexcitability during action observation. Eur I Neurosci 2010;31(5):931-7.

[15] Fadiga L, Fogassi L, Pavesi G, Rizzolatti G. Motor facilitation during action observation: a magnetic stimulation study. J Neurophysiol $1995 ; 73(6): 2608-11$.

[16] Stefan K, Classen J, Celnik P, Cohen LG. Concurrent action observation modulates practice-induced motor memory formation. Eur J Neurosci 2008:27(3):730-8.

[17] Stefan K, Cohen LG, Duque J, Mazzocchio R, Celnik P, Sawaki I, et al. Formation of a motor memory by action observation. J Neurosci 2005;25(41):9339-46.

[18] Neuper C, Pfurtscheller G. Event-related dynamics of cortical rhythms: frequency-specific features and functional correlates. Int J Psychophysiol 2001;43(1):41-58.

[19] Neuper C, Klimesch W, editors. Event-related dynamics of brain oscillations. Progress in brain research, vol. 159. Amsterdam: Elsevier; 2006.

[20] Neuper C, Wörtz M, Pfurtscheller G. ERD/ERS patterns reflecting sensorimotor activation and deactivation. In: Neuper C, Klimesch, editors. Event-related dynamics of brain oscillations. Progress in brain research, 159. Amsterdam: Elsevier; 2006. p. 211-22.

[21] Pfurtscheller G, Aranibar A. Event-related cortical desynchronization detected by power measurements of scalp EEG. Electroencephalogr Clin Neurophysiol 1977;42(6):817-26.

[22] Babiloni C, Babiloni F, Carducci F, Cincotti F, Cocozza G, Del Percio C, et al Human cortical electroencephalography (EEG) rhythms during the observation of simple aimless movements: a high-resolution EEG study. Neurolmage 2002;17(2):559-72.

[23] Calmels C, Holmes P, Jarry G, Leveque JM, Hars M, Stam C]. Cortical activity prior to, and during, observation and execution of sequential finger movements. Brain Topogr 2006;19(1-2):77-88.

[24] Calmels C, Jarry G, Stam CJ. Changes in local and distant EEG activities before: during and after the observation and execution of sequential finger move ments. Neurophysiol Clin 2009:39(6):303-12.

[25] Marshall P], Bouquet CA, Shipley TF, Young T. Effects of brief imitative experience on EEG desynchronization during action observation. Neuropsychologia 2009;47(10):2100-6.

[26] Orgs G, Dombrowski JH, Heil M, Jansen-Osmann P. Expert ise in dance modulates alpha/beta event-related desynchronization during action observation. Eur J Neurosci 2008;27(12):3380-4.

[27] Cochin S, Barthelemy C, Roux S, Martineau J. Observation and execution of movement: similarities demonst rated by quantified electroencephalography. Eur J Neurosci 1999;11(5):1839-42.

[28] Muthukumaraswamy SD, Johnson BW. Primary motor cortex activation during action observation revealed by wavelet analysis of the EEG. Clin Neurophysiol 2004;115(8):1760-6.

[29] Muthukumaraswamy SD, Johnson BW, McNair NA. Mu rhythm modulation during observation of an object-directed grasp. Brain Res Cogn Brain Res 2004; $19(2): 195-201$

[30] Cheng Y, Lee PL, Yang CY, Lin CP, Hung D, Decety ]. Gender differences in the mu rhythm of the human mirror-neuron system. PLoS One 2008;3(5):e2113.

[31] Babiloni C, Marzano N, Infarinato F, lacoboni M, Rizza G, Aschieri P, et al. Neural efficiency of experts' brain during judgment of actions: a highresolution EEG study in elite and amateur karate athletes. Behav Brain Res 2010;207(2):466-75

[32] Pfurtscheller G, NeuperC. Motor imagery activates primary sensorimotor area in humans. Neurosci Lett 1997;239(2-3):65-8.

[33] Pfurtscheller G, Neuper C, Brunner C, da Silva FL. Beta rebound after different types of motor imagery in man. Neurosci Lett 2005;378(3):156-9.

[34] Marks DF, Isaac AR. Topographical distribution of EEG activity accompanying visual and motor imagery in vivid and non-vivid imagers. Br J Psycho 1995:86(Pt 2):271-82. 
[35] Fink A, Graif B, Neubauer AC. Brain correlates underlying creative thinking: EEG alpha activity in professional vs novice dancers. Neurolmage 2009;46(3):854-62.

[36] Horn RR, Williams AM, Hayes SJ, Hodges NJ, Scott MA. Demonstration as a rate enhancer to changes in coordination during early skill acquisition. J Sports Sci 2007:25(5):599-614.

[37] Malouin F, Richards CI. Mental practice for relearning locomotor skills. Phys Ther 2010:90(2):240-51.

[38] Munzert J, Lorey B, Zentgraf K. Cognitive motor processes: the role of motor imagery in the study of motor representations. Brain Res Rev 2009:60(2):306-26

[39] Toussaint L, Blandin Y. On the role of imagery modalities on motor learning. J Sports Sci 2010;28(5):497-504.

[40] Gatti R, Tettamanti A, Gough PM, Riboldi E, Marinoni L, Buccino G. Action observation versus motor imagery in learning a complex motor task: a short review of literature and a kinematics study. Neurosci Lett 2012;540: $37-42$.

[41] Roosink M, Zijdewind I. Corticospinal excitability during observation and imagery of simple and complex hand tasks: implications for motor rehabilitation. Behav Brain Res 2010;213(1):35-41.

[42] Conson M, Sarà M, Pistoia F, Trojano L. Action observation improves motor imagery: specific interactions between simulative processes. Exp Brain Res 2009;199(1):71-81.

[43] Mccormick SA, Causer J, Holmes PS. Active vision during action execution, observation and imagery: evidence for shared motor representations. PLoS One 2013;8(6):e67761.

[44] Gatti R, Rocca MA, Tettamanti A, Filippi M. Evaluation and training of hands and feet movements performed with different strategies: a kinematic study. Clin Neurol Neurosurg 2010;113(3):218-23.

[45] Johansson BB. Current trends in stroke rehabilitation. A review with focus on brain plasticity. Acta Neurol Scand 2010;123(3):147-59.

[46] Sherwood DE, Lee TD. Schema theory: critical review and implications for the role of cognition in a new theory of motor learning. Res Q Exerc Sport 2003;74(4):376-82.

[47] Warner L, McNeill ME. Mental imagery and its potential for physical therapy. Phys Ther 1988;68(4):516-21.

[48] Sailer A, Dichgans ], Gerloff C. The influence of normal aging on the cortical processing of a simple motor task. Neurology 2000;55(7):979-85.

[49] Mackay WA. Wheels of motion: oscillatory potentials in the motor cortex. In: Riehle A, Vaadia E, editors. Motor cortex in voluntary movements: a dis tributed system for distributed functions. Boca Raton, FL: CRC Press; 2005. p. $210-42$

[50] Yi W, Qiu S, Qi H, Zhang L, Wan B, Ming D. EEG feature comparison and classification of simple and compound limb motor imagery. J Neuroeng Rehabil 2013;10:106.

[51] Klimesch W. EEG alpha and theta oscillations reflect cognitive and memory performance: a review and analysis. Brain Res Brain Res Rev 1999;129:169-95.

[52] Leocani L, Toro C, Manganotti P, Zhuang P, Hallett M. Event-related coherence and event-related desynchronization/synchronization in the $10 \mathrm{~Hz}$ and $20 \mathrm{~Hz}$ EEG during self-paced movements. Electroencephalogr Clin Neurophysiol 1997:104:199-206.

[53] Pfurtscheller G, Lopez da Silva FH. Event-related EEG/MEG synchronization and desynchronization: basic principles. Clin Neurophysiol 1999;110(11):1842-57.

[54] Gerloff C, Richard J, Hadley J, Schulman AE, Honda M, Hallett M. Functional coupling and regional activation of human cortical motor areas during simple, internally paced and externally paced finger movements. Brain 1998;121(Pt 8):1513-31.

[55] Pfurtscheller G, Quantification of ERD and ERS in the time domain. In: Pfurtscheller G, Lopes da Silva FH, editors. Event-related desynchronization. Handbook of electroencephalography and clinical neurophysiology, Vol. 6. Amsterdam: Elsevier; 1999. p. 89-105.

[56] Caspers S, Zilles K, Laird AR, Eickhoff SB. ALE meta-analysis of action observation and imitation in the human brain. Neurolmage 2010;50(3):1148-67.

[57] Piefke M, Kramer K, Korte M, Schulte-Rüther M, Korte JM, Wohlschläger AM, et al. Neurofunctional modulation of brain regions by distinct forms of motor cognition and movement features. Hum Brain Mapp 2009;30(2):432-51.

[58] Maeda F, Kleiner-Fisman G, Pascual-Leone A. Motor facilitation while observing hand actions: specificity of the effect and role of observer's orientation. J Neurophysiol 2002;87(3):1329-35.

[59] Urgesic, Candidi M, Fabbro F, Romani M, Aglioti SM. Cabinio Motor facilitation during action observation: topographic mapping of the target muscle and influence of the onlooker's posture. Eur I Neurosci 2006;23(9):2522-30.

[60] Alaerts K, Swinnen SP, Wenderoth N. Is the human primary motor cortex activated by muscular or direction-dependent features of observed movements? Cortex 2009;45(10):1148-55.

[61] Cabinio M, Blasi V, Borroni P, Montagna M, Iadanza A, Falini A, et al. The shape of motor resonance: right- or left-handed? Neurolmage 2010;51(1): 313-23.

[62] Blanke O, Ionta S, Fornari E, Mohr C, Maeder P. Mental imagery for full and upper human bodies: common right hemisphere activations and distinct extrastriate activations. Brain Topogr 2010;23(3):321-32.

[63] Haslinger B, Erhard P, Altenmuller E, Schroeder U, Boecker H, CeballosBaumann AO. Transmodal sensorimotor networks during action observation in professional pianists. J Cogn Neurosci 2005;17(2):282-93.
[64] van Elk M, van Schie HT, Hunnius S, Vesper C, Bekkering H. You'll never crawl alone: neurophysiological evidence for experience-dependent motor resonance in infancy. Neurolmage 2008;43(4):808-14.

[65] Bufalari I, Sforza A, Cesari P, Aglioti SM, Fourkas AD, Motor imagery beyond the joint limits: a transcranial magnetic stimulation study. Biol Psychol 2010;85(2):283-90.

[66] Guillot A, Collet C, Nguyen VA, Malouin F, Richards C, Doyon J. Brain activity during visual versus kinesthetic imagery: an fMRI study. Hum Brain Mapp 2009;30(7):2157-72.

[67] Malouin F, Richards CL, Jackson PL, Dumas F, Doyon J. Brain activations during motor imagery of locomotor-related tasks: a PET study. Hum Brain Mapp 2003;19(1):47-62.

[68] Ross JS, Tkach J, Ruggieri PM, Lieber M, Lapresto E. The mind's eye: functional MR imaging evaluation of golf motor imagery. Am J Neuroradiol 2003;24(6):1036-44

[69] van der Meulen M, Allali G, Rieger SW, Assal F, Vuilleumier P. The influence of individual motor imagery ability on cerebral recruitment during gait imagery. Hum Brain Mapp 2014;35(2):455-70.

[70] Fourkas AD, Bonavolonta V, Avenanti A, Aglioti SM. Kinesthetic imagery and tool-specific modulation of corticospinal representations in expert tennis players, Cereb Cortex 2008;18(10):2382-90.

[71] Cattaneo L, Rizzolatti G. The mirror neuron system. Arch Neurol 2009;66(5):557-60

[72] Fabbri-Destro M, Rizzolatti G. Mirror neurons and mirror systems in monkeys and humans. Physiology (Bethesda) 2008:23:171-9.

[73] Garrison KA, Winstein C], Aziz-Zadeh L. The mirror neuron system: a neural substrate for methods in stroke rehabilitation. Neurorehabil Neural Repair 2010;24(5):404-12.

[74] Kim YT, Seo JH, Song HJ, Yoo DS, Lee HJ, Lee J, et al. Neural correlates related to action observation in expert archers. Behav Brain Res 2011;223(2):342-7.

[75] Gallese V, Fadiga L, Fogassi L, Rizzolatti G. Action recognition in the premotor cortex. Brain 1996;119(Pt 2):593-609.

[76] Fogassi L, Ferrari PF, Gesierich B, Rozzi S, Chersi F, Rizzolatti G. Parietal lobe: from action organization to intention understanding. Science 2005;308(5722):662-7.

[77] Umilta MA, Kohler E, Gallese V, Fogassi L, Fadiga I, Keysers C, et al. I know what you are doing. A neurophysiological study. Neuron 2001;31(1):155-65.

[78] Buccino G, Binkofski F, Fink GR, Fadiga L, Fogassi L, Gallese V, et al. Action observation activates premotor and parietal areas in a somatotopic manner: an fMRI study. Eur J Neurosci 2001:13(2):400-4.

[79] Chong TT, Cunnington R, Williams MA, Kanwisher N, Mattingley JB. fMR adaptation reveals mirror neurons in human inferior parietal cortex. Curr Biol 2008; 18(20):1576-80.

[80] Perry A, Bentin S. Mirror activity in the human brain while observing hand movements: a comparison between EEG desynchronization in the mu-range and previous fMRI results. Brain Res 2009;1282:126-32.

[81] Buccino G, Vogt S, Ritzl A, Fink GR, Zilles K, Freund H], et al. Neural circuits underlying imitation learning of hand actions: an event-related fMRI study. Neuron 2004:42(2):323-34.

[82] Androulidakis AG, Doyle LM, Yarrow K, Litvak V, Gilbertson TP, Brown P. Anticipatory changes in beta synchrony in the human corticospinal system and associated improvements in task performance. Eur J Neurosc 2007:25(12):3758-65.

[83] Pfurtscheller G, Neuper C, Andrew C, Edlinger G. Foot and hand area mu rhythms. Int J Psychophysiol 1997;26(1-3):121-35.

[84] Pfurtscheller G, Brunner C, Schlögl A, Lopes da Silva FH. Mu rhythm (de)synchronization and EEG single-trial classification of different motor imagery tasks. Neurolmage 2006;31(1):153-9.

[85] Alemanno F, Houdayer E, Cursi M, Velikova S, Tettamanti M, Comi G, et al. Action-related semantic content and negation polarity modulate motor areas during sentence reading: an event-related desynchronization study. Brain Res 2012;1484:39-49.

[86] Benedek M, Bergner S, Könen T, Fink A, Neubauer AC. EEG alpha synchronization is related to top-down processing in convergent and divergent thinking Neuropsychologia 2011;49(12):3505-11.

[87] Cooper NR, Croft RJ, Dominey SJ, Burgess AP, Gruzelier JH. Paradox lost? Exploring the role of alpha oscillations during externally vs, internally directed attention and the implications for idling and inhibition hypotheses. Int J Psychophysiol 2003;47(1):65-74.

[88] lacoboni M, Woods RP, Brass M, Bekkering H, Mazziotta JC, Rizzolatti G. Cortical mechanisms of human imitation. Science 1999;286(5449):2526-8.

[89] Arnstein D, Cui F, Keysers C, Maurits NM, Gazzola V. $\mu$-Suppression during action observation and execution correlates with BOLD in dorsal premotor, inferior parietal, and SI cortices. J Neurosci 2011:31(40):14243-9.

[90] Holtz EM, Doppelmayr M, Klimesch W, Sauseng P. EEG correlates of action observation in humans. Brain Topogr 2008;21(2):93-9.

[91] Neuper C, Scherer R, Reiner M, Pfurtscheller G. Imagery of motor actions: differential effects of kinesthetic and visual-motor mode of imagery in singletrial EEG. Brain Res Cogn Brain Res 2005;25(3):668-77.

[92] Callow N, Hardy L. The relationship between the use of kinaesthetic imagery and different visual imagery perspectives, J Sports Sci 2004:22(2):167-77.

[93] Dickstein R, Deutsch JE. Motor imagery in physical therapist practice. Phys Ther 2007; 7:942-53.

[94] Solodkin A, Hlustik P, Chen EE, Small SL. Fine modulation in network activation during motor execution and motor imagery. Cereb cortex 2004:14:1246-55. 
[95] Parsons LM. Temporal and kinematic properties of motor behavior reflected in mentally simulated action. J Exp Psychol Hum Percept Perform 1994;20(4):709-30.

[96] De Smedt B, Grabner RH, Studer B, Oscillatory EEG correlates of arithmetic strategy use in addition and subtraction. Exp Brain Res 2009;195(4):635-42.

[97] Dimitriadis SI, Laskaris NA, Tsirka V, Vourkas M, Micheloyannis S. What does delta band tell us about cognitive processes: a mental calculation study. Neurosci Lett 2010;483(1):11-5.

[98] Harmony T, Fernandez T, Silva J, Bernal J, Díaz Comas L, Reyes A, et al. EEG delta activity: an indicator of attention to internal processing during performance of mental tasks. Int J Psychophysiol 1996;24(1-2):161-71.

[99] Rizzolatti G, Craighero L. The mirror-neuron system. Annu Rev Neurosci 2004;27:169-92.

[100] Wohlschläger A, Gattis M, Bekkering H. Action generation and action perception in imitation: an instance of the ideomotor principle. Philos Trans R Soc London B Biol Sci 2003;358(1431):501-15.

[101] Pfurtscheller G. Event-related synchronization (ERS): an electrophysiological correlate of cortical areas at rest. Electroencephalogr Clin Neurophysiol $1992 ; 83(1): 62-9$.

[102] Pfurtscheller G, Neuper C. Event-related synchronization of mu rhythm in the EEG over the cortical hand area in man. Neurosci Lett 1994:174(1):93-6.

[103] Leocani L, Toro C, Zhuang P, Gerloff C, Hallett M. Event-related desynchronization in reaction time paradigms: a comparison with event-related potentials and corticospinal excitability. Clin Neurophysiol 2001;112(5):923-30.

[104] Pfurtscheller G. Functional brain imaging based on ERD/ERS. Vision Res 2001;41(10-11):1257-60.

[105] Leocani L, Toro C, Manganotti P, Zhuang P, Hallett M. Event-related coherence and event-related desynchronization/synchronization in the $10 \mathrm{~Hz}$ and $20 \mathrm{~Hz}$ EEG during self-paced movements. Electroencephalogr Clin Neurophysiol 1997;104(3):199-206.

[106] Pfurtscheller G, Stancak Jr A, Neuper C. Postmovement beta synchronization. A correlate of an idling motor area? Electroencephalogr Clin Neurophysiol $1996 ; 98(4): 281-93$

[107] Hatfield BD, Haufler AJ, Hung TM, Spalding TW. Electroencephalographic studies of skilled psychomotor performance. J Clin Neurophysiol 2004:21(3):144-56.

[108] Rietschel JC, Miller MW, Gentili R], Goodman RN, McDonald CG, Hatfield $\mathrm{BD}$. Cerebral-cortical networking and activation increase as a function of cognitive-motor task difficulty. Biol Psychol 2012:90(2):127-33.

[109] Swann N, Tandon N, Canolty R, Ellmore TM, McEvoy LK, Dreyer S, et al. Intracranial EEG reveals a time- and frequency-specific role for the right inferior frontal gyrus and primary motor cortex in stopping initiated responses. J Neurosci 2009;29(40):12675-85.

[110] Zhang Y, Chen Y, Bressler SL, Ding M. Response preparation and inhibition: the role of the cortical sensorimotor beta rhythm. Neuroscience 2008:156(1):238-46.

[111] Pfurtscheller G, Zalaudek K, Neuper C. Event-related beta synchronization after wrist: finger and thumb movement. Electroencephalogr Clin Neurophysiol 1998;109(2):154-60.

[112] Steriade M, McCormick DA, Sejnowski T]. Thalamocortical oscillations in the sleeping and aroused brain. Science 1993;262(5134):679-85.
[113] Kristeva-Feige R, Fritsch C, Timmer J, Lücking CH. Effects of attention and precision of exerted force on beta range EEG-EMG synchronization during a maintained motor contraction task. Clin Neurophysiol 2002;113(1):124-31.

[114] Cassim F, Monaca C, Szurhaj W, Bourriez JI, Defebvre L, Derambure P, et al, Does post-movement beta synchronization reflect an idling motor cortex? NeuroReport 2001;12(17):3859-63.

[115] Keinrath C, Wriessnegger S, Müller-Putz GR, Pfurtscheller G, Post-movement beta synchronization after kinesthetic illusion: active and passive move ments. Int J Psychophysiol 2006;62(2):321-7.

[116] Baker SN. Oscillatory interactions between sensorimotor cortex and the periphery. Curr Opin Neurobiol 2007;17(6):649-55.

[117] Engel AK, Fries P. Beta-band oscillations - signalling the status quo? Curr Opin Neurobiol 2010;20(2):156-65.

[118] Jenkinson N, Brown P. New insights into the relationship between dopamine: beta oscillations and motor function. Trend Neurosci 2011;43(12): 611-8.

[119] Kühn AA, Doyle L, Pogosyan A, Yarrow K, Kupsch A, Schneider GH, et al. Modulation of beta oscillations in the subthalamic area during motor imagery in Parkinson's disease, Brain 2006;129(Pt 3):695-706.

[120] Floyer-Lea A, Matthews PM. Changing brain networks for visuomotor control with increased movement automaticity. J Neurophysiol 2004;92(4): 2.405-12.

[121] Karni A, Meyer G, Rey-Hipolito C, Jezzard P, Adams MM, Turner R, et al. The acquisition of skilled motor performance: fast and slow experience-driven changes in primary motor cortex. Proc Natl Acad Sci USA 1998;5(3):861-8.

[122] Kelly AM, Garavan H. Human functional neuroimaging of brain changes asso ciated with practice. Cereb Cortex 2005;15(8):1089-102.

[123] Olesen PJ, Westerberg H, Klingberg T. Increased prefrontal and parietal activity after training of working memory. Nat Neurosci 2004;7(1):75-9.

[124] Sacco K, Cauda F, Cerliani L, Mate D, Duca S, Geminiani GC. Motor imagery of walking following training in locomotor attention. The effect of the tango lesson. Neurolmage 2006;32(3):1441-9.

[125] Manganotti P, Gerloff C, Toro C, Katsuta H, Sadato N, Zhuang P, et al Task-related coherence and task-related spectral power changes during sequential finger movements. Electroencephalogr Clin Neurophysiol 1998:109(1):50-62.

[126] Zhuang P, Toro C, Grafman J, Manganotti P, Leocani L, Hallett M. Event related desynchronization (ERD) in the alpha frequency during development of implicit and explicit learning. Electroencephalogr Clin Neurophysiol 1997:102(4):374-81.

[127] Cross ES, Stadler W, Parkinson J, Schütz-Bosbach S, Prinz W. The influence of visual training on predicting complex action sequences. Hum Brain Mapp 2013;34(2):467-86.

[128] Debaere F, Wenderoth N, Sunaert S, Van Hecke P, Swinnen SP. Changes in brain activation during the acquisition of a new bimanual coodination task. Neuropsychologia 2004;42(7):855-67.

[129] Remy F, Wenderoth N, Lipkens K, Swinnen SP. Acquisition of a new bimanual coordination pattern modulates the cerebral activations elicited by an intrinsic pattern: an fMRI study. Cortex 2008;44(5):482-93.

[130] Wolpert DM, Diedrichsen J, Flanagan JR. Principles of sensorimotor learning. Nat Rev Neurosci 2011;12(12):739-51. 